\title{
Developing a Fuzzy Analytic Hierarchy Process for Choosing the Energetically Optimal Solution at the Early Design Phase of a Building
}

\author{
András Szüts, István Krómer \\ Óbuda University \\ Bécsi út 96/b, H-1034 Budapest, Hungary \\ szuts.andras@phd.uni-obuda.hu, kromer.istvan@kvk.uni-obuda.hu
}

\begin{abstract}
Reducing the energy consumption of households and making them more energy efficient are indispensable for fulfilling the European Union's energy strategy since more than one-third of total EU energy use is consumed by households. Our research here focuses on the development of building design methods since, decisions made during the early design phase significantly affect the energy consumption and energy efficiency of the building. In Hungary, current simulation methods are not sufficiently effective in evaluating potential alternatives in the early design process; therefore, in our research, we look for new solutions based on decision support systems. In our view, either a classic AHP or a Hybrid Fuzzy AHP based system could fulfil this task. In this article, we will demonstrate the structure and use of the developed systems, and we will compare them to the simulation methods commonly used nowadays. Further, we will test and evaluate the performance of the decision support system based models developed by us, applying them to four typical buildings in Hungary. Lastly, we will propose opportunities for further development.
\end{abstract}

Keywords: fuzzy logic controllers; analytic hierarchy process; energy; households

\section{Introduction}

In Hungary and in the European Union, households consume more than one-third of the total energy usage; thus, it is obvious that in order to achieve EU energy policy objectives, to enhance energy efficiency, and to make more secure the energy supply, it is necessary to reduce household consumption. To reduce residential energy consumption, the European Union has developed multiple strategies, which will be described later. There are several suitable methods for solving the energy efficiency problems related to household energy consumption, as well as combinations of these. In our research, we focus on the development of design methods to increase energy efficiency during this phase. 
Currently in Hungarian building design practices, very little attention is paid to energy efficiency, and, unfortunately, building planners generally seek only to meet the requirements of the law. Consequently there are only a few exemplary projects of energy efficiency in the country [1]. This scarcity of attention is due to a lack of regulation, as well as to the very high price sensitivity of Hungarian consumers, as compared to Western Europe. Given this situation, it would be beneficial to improve the design process and to modify the design methods in such a way that the designer is able to effectively and tangibly demonstrate the energy efficiency choices made and the long-term benefits of the different alternatives. With a more effective planning method, it might be possible during the design process to achieve the highest possible energy efficiency without causing an excessive increase in cost to the customer or investor, and without asking the impossible of the designer. It is important to note that in our research we concentrate on the early, conceptual stage of the building design process, because the decisions taken in this phase have the greatest influence on the energy consumption and energy efficiency of the planned or renovated building. The goal of the models developed is to rank the different building concepts developed in the early planning stages.

\section{Energy Policy Objectives, the Available Saving Potential in the Sector}

Over the past few years and decades, the European Union has announced several targets regarding environmental protection and energy awareness. The first significant action on the matter was Directive 20/20/20, which sets three legally binding targets for 2020: a 20\% reduction in greenhouse gas emissions from 1990 levels; raising the share of EU energy consumption from renewable sources to $20 \%$; and a $20 \%$ improvement in the EU's energy efficiency [2]. As a further step, the EU developed a long-term energy strategy that seeks by the year 2050 an 8095\% reduction in greenhouse gas emissions compared to the base year 1990 [3]. Accordingly, from the year 2021 the standard expectation for new buildings is that they will be nearly zero energy use buildings [4]. However, these strict requirements for new buildings do not themselves alone ensure the attainment of the climate and energy policy goals. Therefore, it is worth examining what degree of savings potential we have for existing and new buildings in the future, and in what proportion the different fields of application will share these various savings.

In our research, we have examined in detail the structure and the inherent savings potential in household energy consumption. Based on analyses made in the European Union, it can be established that the total household sector up to the year 2050 has a saving potential of $71 \%$ [5]. The potential savings can be realized in the following areas: 
- Construction of new buildings (14\%),

- Renovation of existing building structures (29\%),

- Modernization of heating systems (16\%),

- Modernization of the domestic hot water supply systems (4\%),

- Lighting energy efficiency (4\%)

- Energy efficiency of electrical equipment (4\%).

Based on the preceding findings, it is clear that a significant proportion of the available savings potential is related to the energy efficient renovation and transformation of existing buildings. This supports the statement made above that strict regulations for new buildings alone will not be sufficient for achieving the desired objectives. It would clearly be useful to encourage investors and owners in complex energy developments to improve energy efficiency in the very conception of these projects, and not only in the changing and/or renovating of certain structures and equipment, as is currently the practice. We would also emphasize the finding that a $4 \%$ energy savings could be achieved via the energy requirements of lighting, while another $4 \%$ of savings could be achieved by increasing the efficiency of electrical equipment (meanwhile noting that, according to current legislation, the energy demands of lighting and electrical equipment need not be included in the energy balance of residential and housingtype buildings) [6]. Considering this $8 \%$ potential, investments made in these areas could yield the earliest returns from energy savings.

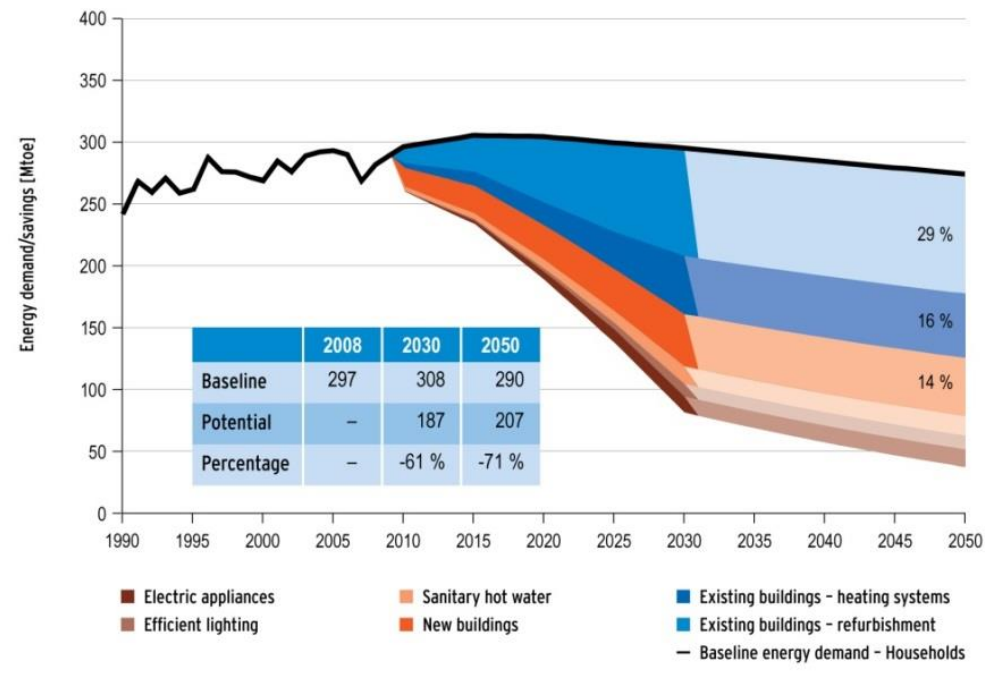

Figure 1

Total final energy saving potentials in the household sector in the EU [source: Fraunhofer ISI, 5] 


\section{New Design Methods}

Knowing the available savings potential, we should examine the factors that affect a household's energy consumption, factors which - in our opinion - can be divided into two separate groups. One group of factors includes consumer behaviour and habits, an area almost completely ignored in current design practices. The other group is composed of technical and other design variables. In our previous research we have already dealt with the uncertainties arising from consumer habits. We created an artificial neural network based inference system that can help estimate the annual primary energy consumption of a household based on statistics. This system makes manageable the uncertainties arising from consumer habits [1]. This current article therefore focuses on technical issues and other design variables.

Examining the group of the factors mentioned above, in our research we analyzed the design process, paying particular attention to the decision-making processes during planning. Having examined current Hungarian design practices, we can conclude that, in the early planning stages, decision-makers generally rely on their experience, rather than on facts or data supported by decision support systems. Therefore, it would be beneficial to develop a decision support system that would help both the designer and the developer in the early stages of planning to choose the optimal variants as regards energy efficiency. In order for the decision support model to actually be adopted, it should have relatively low resource demand as well as high speed and wide applicability. As regards energy awareness, in the prevailing design practice, both simple and complex current simulation models can only be used and give accurate results when all technical and design variables are already known. Therefore, the use of these available simulation models during the conceptual design phase is problematic, given their questionable accuracy and effectiveness at this stage and the labour-intensiveness of their use. In the process of our research, in order to identify an applicable decision support model, we examined multiple international, describable decision problems similar to those faced in the building design process, and we have identified a widely used model for multi-criteria decision-making problems, the Analytic Hierarchy Process (AHP).

\section{The Classical Analytic Hierarchy Process}

The backbone of the classical AHP model is the hierarchical structure of factors, criteria and alternatives [7]. During the decision-making process, it will express the joint conclusion of multiple experts as to the optimal solution. Accordingly, we determined the factors affecting the energy consumption of a household and grouped them into a hierarchical system. 
The main criteria are as follows:

- Conceptual efficiency,

- The performance of the building structures,

- The energy efficiency of the equipment,

- Architectural value, design,

- Interior comfort,

- Lifetime and reliability.

The sub-criteria of the conceptual efficiency are: the building's orientation, the window to wall ratio (including the doors also), the shading ratio of the windows, the shape of the roof, and ratio of attic built in. By the performance of the building structures we mean the thermal properties of the different structures. As for the energy efficiency of the equipment, we look at the energy efficiency of the house's total fixtures, as well as the amount of consumption supplied by renewable energy sources. The architectural value, which includes the fit to the environment, and the functional design of the building could be important factors for both the customer and the designer, since it will not matter if the building achieves near zero energy demand if the customer does not like it and chooses a different alternative. Interior comfort refers to the heating, cooling and lighting demand. Lifetime and reliability refer to the longevity and maintainability of all structures and equipment considered in the other main criteria. Another important criterion is investment cost, but at this stage of our work we have not yet integrated this criterion into our research, similarly to other international researchers [8]. The pay-off of the investments strongly depends on energy prices and thus needs to be inspected separately, which is not the subject of this article. At the same time, Hungarian consumers are very price sensitive, and therefore investment costs would weigh extremely high in the AHP hierarchy compared to the other factors, and this would significantly affect and distort the results. Therefore, the question of costs is treated separately from the AHP model during the development. The built AHP structure is shown in Figure 2.

Applying the classical AHP method, the decision makers use the pairwise comparison matrix to evaluate the different alternatives according to the set criteria [7]. In the pairwise comparisons we used the basic Saaty scale, skipping the intermediate values, as using a wider scale than 5 grades could lead to inadequate evaluation for this problem. The elements in the used scale are as follows [7]:

- 1. Equally preferred,

- 3. Moderately preferred,

- 5. Strongly preferred,

- 7. Very strongly preferred,

- 9. Extremely preferred. 


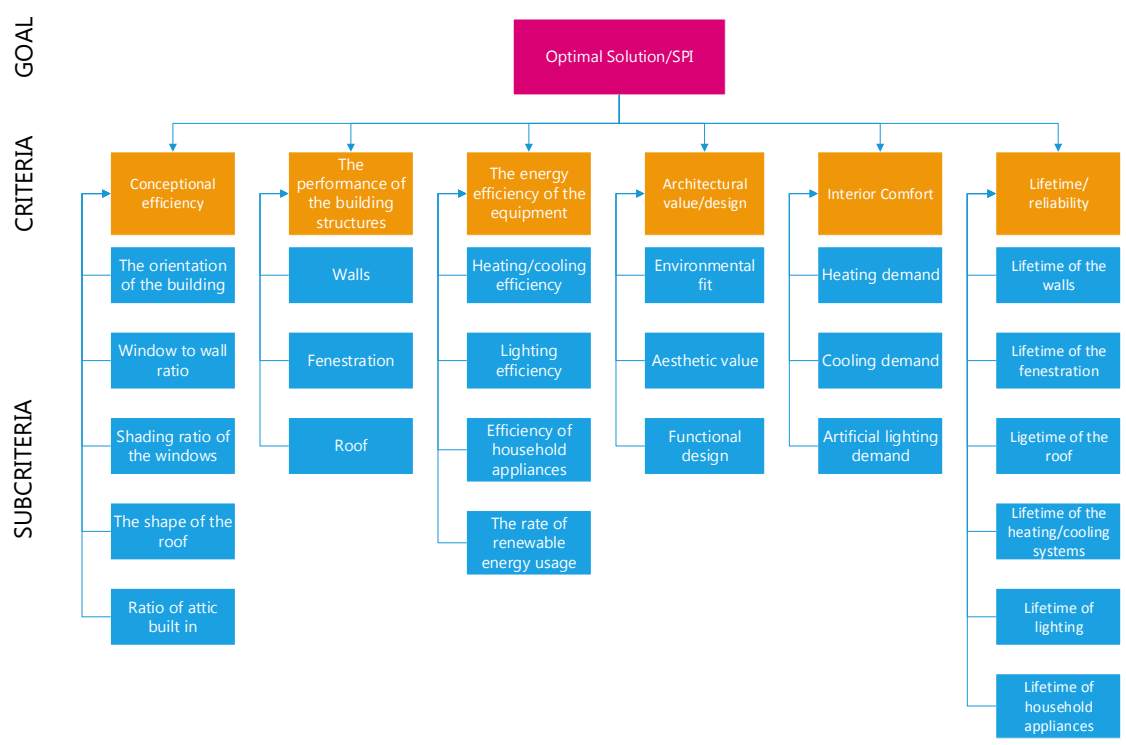

Figure 2

The AHP hierarchy

Table 1

An example for the pairwise comparison matrix

\begin{tabular}{|l|r|r|r|r|}
\cline { 2 - 5 } \multicolumn{1}{c|}{} & A1 & \multicolumn{1}{c|}{ A2 } & \multicolumn{1}{c|}{ A3 } & \multicolumn{1}{c|}{ A4 } \\
\hline A1 & - & 0,333 & 0,333 & 0,111 \\
\hline A2 & 3 & - & 1 & 0,111 \\
\hline A3 & 3 & 1 & - & 0,111 \\
\hline A4 & 9 & 9 & 9 & - \\
\hline
\end{tabular}

According to the value in the first column, second row of the sample pairwise comparison matrix seen in Table 1, the specified properties of alternative A2 are moderately preferred compared to the same properties of alternative A1. Considering the elements in the second column, third row, the alternatives A2 and A3 are equal as regards the specified properties.

For the proper application of the model, it is necessary to define the participants in the decision-making process. Examining the process of a construction project, in the concept design stage the following decision-makers need to be considered:

- Investor/Resident,

- Architect,

- Authority. 
After, preparing the pairwise comparisons, to determine the weight of the criteria and sub-criteria, as well as to set up the ranking, we use the open source, Javabased "Priority Estimation Tool (AHP)" software, based on the eigenvector method.

\section{The Hibrid Fuzzy AHP System}

Using the classical AHP method, described in the previous paragraph, it can be concluded that the preparation of the pairwise comparisons is a highly laborintensive process, and therefore its effectiveness is questionable. The weakness of the method in the described case is the high number of criteria and sub-criteria. If we consider the four different alternatives, a number, which is not unusual during the concept design phase, the three decision-makers must prepare a total of 90 pairwise comparison matrixes, which is not particularly good in terms of effectiveness of decision-making. Therefore, it is necessary to develop the method further for the more general and more efficient applicability.

To eliminate the problems mentioned above, we have developed a Hybrid Fuzzy AHP system on the foundations of the described classical AHP model. In the revised model we have left the above described AHP structure, along with the specified criteria and sub-criteria; however, for the evaluation of the alternatives, we did not use the pairwise comparison matrix as input data, but rather the SPIs (Site Performance Index) calculated from fuzzy inference systems. These SPIs are values between 0 and 1 for standardized input and calculated from the appropriate attributes of the selected alternative. The two-level AHP structure is evaluated according to the classical method with pairwise comparisons, weighted with the aggregated opinion of the experts involved. The formed hierarchical structure is, therefore, weighted in a general sense, and due to this, the alternatives to be ranked with their specified data can be evaluated without expert assistance. Figure 3 shows an example of a fuzzy logic controller input, namely the case of the SPI based on the roof pitch and the amount of attic built in. To create the fuzzy control systems, the Matlab "Fuzzy Logic Toolbox" module was used. 


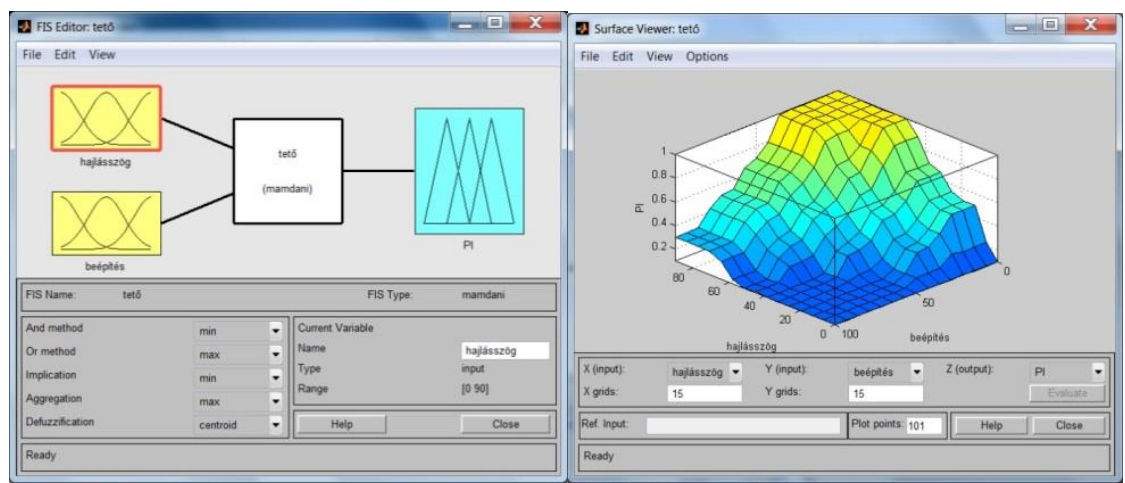

Figure 3

One of the fuzzy logic controllers (FLC)

The full Hybrid Fuzzy AHP model for easy application was created in the Matlab "Simulink" module, and thus hundreds of different alternatives can easily be evaluated and ranked. The "Simulink" model pattern is illustrated in Figure 4. As shown in the figure, in the case of the architectural value criteria, we did not apply the fuzzy controllers at the input side since during the subjective evaluation, system-matching scores had already been generated, and therefore there was no need to convert the data and manage the uncertainties. In our case, it is highly probable that the opinion of the decision-maker with regard to the defined criteria will be measured precisely. 


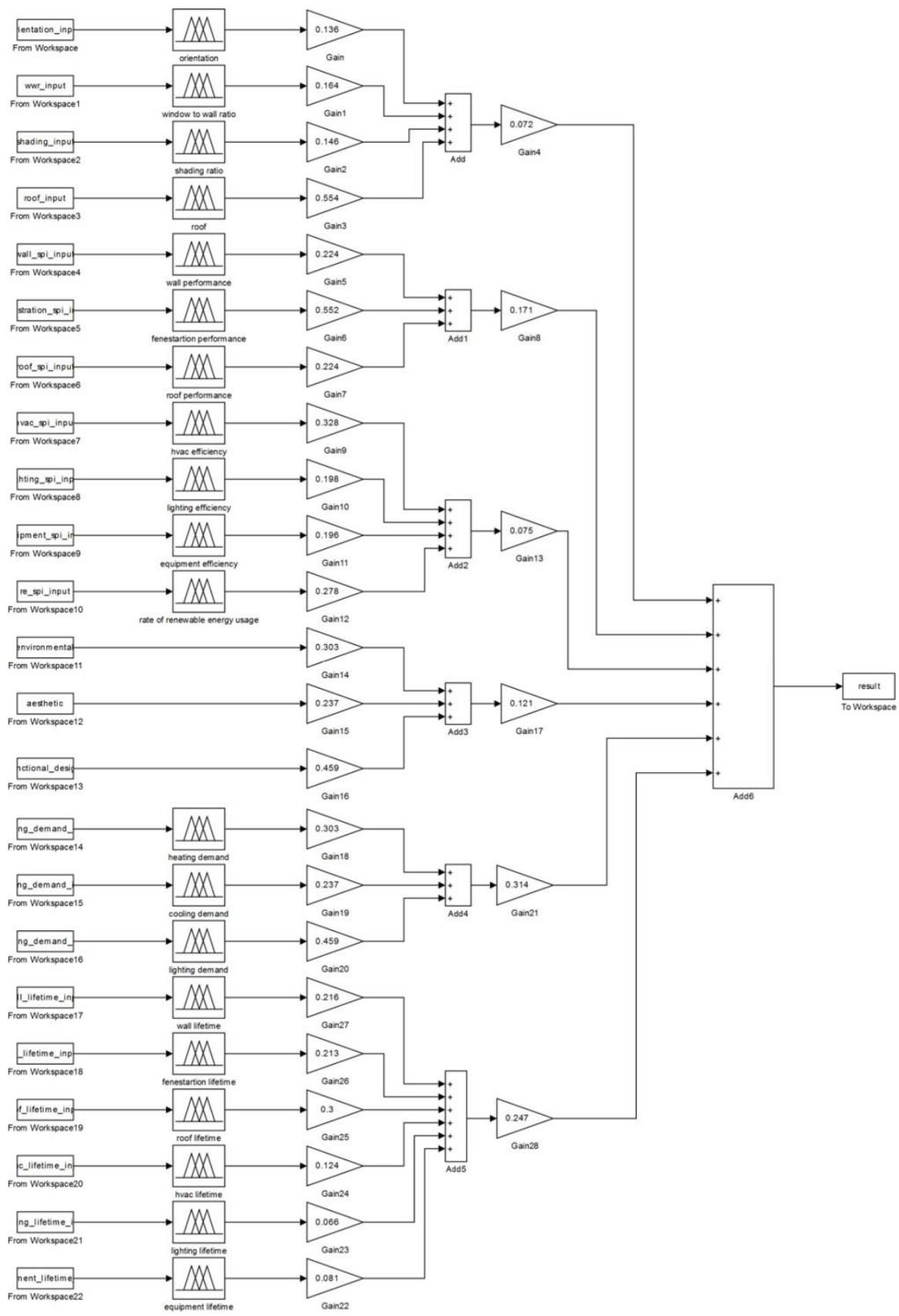

Figure 4

The Simulink modell of the hibrid Fuzzy-AHP system 


\section{Validation}

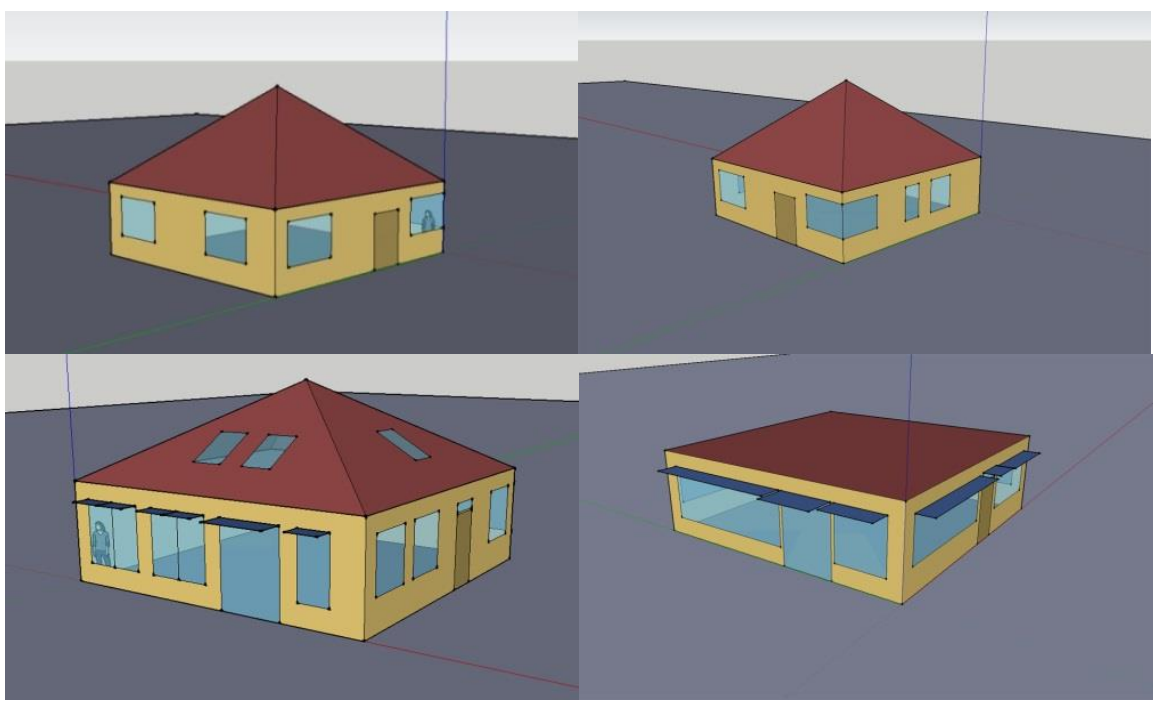

Figure 5

The 3D models of the A1-A4 alternatives (Google SketchUp, OpenStudio)

In order to evaluate the models, we prepared a detailed energy simulation of four typical buildings in Hungary and we evaluated them with the proposed methods and systems. We did the detailed simulation of the alternatives with Open Studio and EnergyPlus software developed by the National Renewable Energy Laboratory, which are widely used in international research [9, 10]. During modelling we prepared realistic, three-dimensional models of the buildings, and we performed the energy simulations in accordance with the given criteria, based on the actual annual meteorological data. The data of the different alternatives systematized according to the AHP structure are included in Table 2. We determined the orientation of the building by the location of the main rooms of the building (living room and dining room). As for the lifetime of the different structures and fixtures, we mean the achievable maximum durability with appropriate and necessary maintenance.

Table 2

The 4 alternatives

\begin{tabular}{lrrrrr} 
& \multicolumn{5}{c}{ Alternatives } \\
Criteria & A1 & A2 & A3 & \multicolumn{1}{c}{ A4 } \\
Conceptional efficiency & & & & & \\
The orientation of the building & 0 & 90 & 180 & 270 & {$\left[{ }^{\circ}\right] N-O^{\circ}$} \\
Window to wall ratio & 0,18 & 0,18 & 0,25 & 0,43 & \\
Shading ratio of the windows & 0,00 & 0,00 & 0,52 & 1,00
\end{tabular}




\begin{tabular}{|c|c|c|c|c|c|}
\hline The shape of the roof & 38,83 & 38,83 & 30,00 & 5,00 & {$\left[{ }^{\circ}\right]$} \\
\hline Ratio of attic built in & 0,00 & 0,00 & 0,50 & 0,00 & \\
\hline $\begin{array}{l}\text { The performance of the building } \\
\text { structures }\end{array}$ & A1 & A2 & $\mathbf{A 3}$ & A4 & \\
\hline Performance of the walls & 1,790 & 0,391 & 0,242 & 0,136 & {$\left[W / m^{2} K\right]$} \\
\hline Performance of the fenestration & 2,200 & 1,600 & 1,600 & 0,800 & {$\left[\mathrm{~W} / \mathrm{m}^{2} \mathrm{~K}\right]$} \\
\hline Performance of the roof & 1,690 & 1,690 & 0,740 & 0,115 & {$\left[W / m^{2} K\right]$} \\
\hline $\begin{array}{l}\text { The energy efficiency of the } \\
\text { equipment }\end{array}$ & A1 & A2 & $\mathbf{A 3}$ & A4 & \\
\hline Heating/cooling efficiency & 0,80 & 0,80 & 1,00 & 1,50 & \\
\hline Lighting efficiency & 10,50 & 10,50 & 7,00 & 5,25 & {$\left[W / m^{2}\right]$} \\
\hline Efficiency of household appliances & 3,45 & 3,45 & 2,30 & 1,80 & {$\left[\mathrm{~W} / \mathrm{m}^{2}\right]$} \\
\hline The rate of renewable energy usage & 0,00 & 0,00 & 0,10 & 0,20 & \\
\hline Architectural value/design & A1 & A2 & A3 & A4 & \\
\hline Environmental fit & 0,20 & 0,20 & 0,50 & 1,00 & \\
\hline Aesthetic value & 0,20 & 0,20 & 0,30 & 0,80 & \\
\hline Functional design & 0,50 & 0,50 & 0,40 & 0,60 & \\
\hline Interior comfort & A1 & A2 & A3 & A4 & \\
\hline Heating demand & 22 & 21 & 20 & 21 & {$\left[{ }^{\circ}\right]$} \\
\hline Cooling demand & - & - & 25 & 24 & {$\left[0^{\circ}\right]$} \\
\hline Artificial lighting demand & 13 & 13 & 11 & 8 & [hour] \\
\hline Lifetime/reliability & A1 & A2 & A3 & A4 & \\
\hline Lifetime of the walls & 10 & 15 & 25 & 50 & [year] \\
\hline Lifetime of the fenestration & 5 & 10 & 10 & 25 & [year] \\
\hline Lifetime of the roof & 5 & 15 & 25 & 25 & [year] \\
\hline $\begin{array}{l}\text { Lifetime of the heating/cooling } \\
\text { system }\end{array}$ & 5 & 10 & 10 & 15 & [year] \\
\hline Lifetime of lighting & 2 & 2 & 5 & 10 & [year] \\
\hline Lifetime of household appliances & 10 & 10 & 5 & 10 & [year] \\
\hline
\end{tabular}

After the energy simulation of the above-described alternatives we evaluated them with the classical AHP model and with the proposed Hybrid Fuzzy AHP model. With the classical AHP model, the specified decision-makers prepared the pairwise comparison matrix with regard to all the specified criteria and alternatives, and then with the already mentioned software we set up the ranking of the various alternatives. When the Fuzzy AHP hybrid system was applied, the decision-makers only prepared the pairwise comparison matrix in case of the criteria, while the evaluation of the alternatives were managed with the SPIs defined by fuzzy inference system in the hierarchical system, where the weights had already been determined. Based on the resulting ranking and weighting of the alternatives in the AHP, we could easily evaluate the results. 


\section{Results}

Using the methods described above, during the evaluation of the alternatives A1 to A4, we obtained the results shown in Table 3. In order to get a better overview, the simulated energy consumption of the alternatives is shown on the table according to the different consumption areas. The primary energy conversion factors have been applied according to current Hungarian legislation. The estimated costs in the case of the evaluated alternatives were based on the currently valid Hungarian construction statistics data.

Table 3

The results

\begin{tabular}{|c|c|c|c|c|c|}
\hline Simulation results & A1 & A2 & A3 & A4 & \\
\hline \multicolumn{6}{|l|}{ Energy consumption } \\
\hline HVAC systems (natural gas) & 1093 & 798 & 648 & 0 & {$\left[\mathrm{MJ} / \mathrm{m}^{2}\right]$} \\
\hline Water systems (natural gas) & 224 & 224 & 110 & 143 & {$\left[\mathrm{MJ} / \mathrm{m}^{2}\right]$} \\
\hline Total (natural gas) & 1317 & 1022 & 757 & 143 & {$\left[\mathrm{MJ} / \mathrm{m}^{2}\right]$} \\
\hline HVAC systems (electric) & 14 & 8 & 54 & 179 & {$\left[\mathrm{MJ} / \mathrm{m}^{2}\right]$} \\
\hline Lighting (electric) & 109 & 54 & 71 & 46 & {$\left[\mathrm{MJ} / \mathrm{m}^{2}\right]$} \\
\hline Other (electric) & 72 & 37 & 48 & 37 & {$\left[\mathrm{MJ} / \mathrm{m}^{2}\right]$} \\
\hline Total (electric) & 194 & 99 & 173 & 262 & {$\left[\mathrm{MJ} / \mathrm{m}^{2}\right]$} \\
\hline Total (net) & 1511 & 1121 & 930 & 405 & {$\left[M J / m^{2}\right]$} \\
\hline Total (primary energy) & 1803 & 1270 & 1070 & 638 & {$\left[\mathbf{M J} / \mathbf{m}^{2}\right]$} \\
\hline Investment costs & 661 & 981 & 1384 & 3181 & {$\left[€ / \mathbf{m}^{2}\right]^{*}$} \\
\hline Energy scores & 0,14 & 0,20 & 0,24 & 0,41 & $\begin{array}{l}\text { [normalized } \\
\text { results] }\end{array}$ \\
\hline Classic AHP results & 0,110 & 0,143 & 0,240 & 0,506 & \\
\hline Deviation from the energy scores & $-23,78$ & $-30,17$ & $-1,30$ & 24,10 & {$[\%]$} \\
\hline Fuzzy AHP results & $\mathbf{0 , 3 7 0}$ & 0,487 & 0,575 & 0,818 & \\
\hline Fuzzy AHP normalized results & 0,164 & 0,216 & 0,256 & 0,364 & $\begin{array}{l}\text { [normalized } \\
\text { results] }\end{array}$ \\
\hline Deviation from the energy scores & 13,95 & 5,69 & 5,10 & $-10,83$ & {$[\%]$} \\
\hline
\end{tabular}

Based on the results obtained, it can be seen that all three methods of considering the alternatives result in the same ranking; so by simply considering these rankings, we can conclude that both the classical AHP method and the hybrid Fuzzy AHP method are suitable for evaluating the alternatives that arise in the early design phase. Considering the accuracy of the method, and in particular analysing the results achieved in energy efficiency, it can be stated that our proposed hybrid Fuzzy AHP system differed by only 13.95\% from the detailed simulation in the worst case, while the classic AHP differed by more than $30 \%$ in one case. This may be explained by the fact that with the classic AHP, the 
subjective (lay) evaluation is emphasised more than in the proposed Fuzzy-AHP based expert system. Thus, the system with the fuzzy controllers also appears to have the advantage of eliminating any lack of knowledge on the part of the individual decision-makers.

\section{Conclusions}

The characteristics of the used methods are summarized in Table 4. Based on the comparison, it can be seen that our proposed Fuzzy-AHP hybrid system is the most efficient, as regards the labour requirement. The system created is sufficiently precise in the early, concept stage of the design, and therefore it can constitute an alternative to energy simulations made at this stage. There is the slight disadvantage of the need to design the system for local conditions, with the consequent high resource demand, but in our opinion, the fast running speed and the low labour and resource requirements during application compensate for this disadvantage.

Table 4

The comparasion of the applied systems

\begin{tabular}{|l|c|c|c|}
\hline Criteria & Simulation & Classic AHP & Fuzzy AHP \\
\hline \hline $\begin{array}{l}\text { Ability to evaluate the } \\
\text { subjective criteria }\end{array}$ & Not possible & Adequate & Adequate \\
\hline $\begin{array}{l}\text { Labor demand during } \\
\text { application }\end{array}$ & Very high & High & Low \\
\hline Model complexity & Very complex & Simple & Complex \\
\hline Running speed & Slow & Fast & Fast \\
\hline Accuracy & Very accurate & $\begin{array}{c}\text { Moderately } \\
\text { accurate }\end{array}$ & Accurate \\
\hline $\begin{array}{l}\text { Labor demand to develop } \\
\text { the system }\end{array}$ & High & Low & High \\
\hline
\end{tabular}

It is important to note that neither the development of design systems to reduce the energy consumption of buildings and households nor increasing a building's energy efficiency is enough to achieve EU energy objectives. In our opinion, in addition to appropriate regulation and effective design methods, it is also necessary to increase the interest of consumers (tenants, investors), encouraging their demand for energy efficiency, since, only the combination of these three factors can achieve the desired change in energy efficiency.

\section{Acknowledgement}

This work was supported by Doctoral School of Applied Informatics and Applied Mathematics of Óbuda University. 


\section{References}

[1] András Szűts, István Krómer: Estimating Hungarian Household Energy Consumption Using Artificial Neural Networks, Acta Polytechnica Hungarica, Vol. 11, No. 4, pp. 155-168, 2014

[2] DIRECTIVE 2009/28/EC OF THE EUROPEAN PARLIAMENT AND OF THE COUNCIL: on the promotion of the use of energy from renewable sources and amending and subsequently repealing Directives 2001/77/EC and 2003/30/EC, 23.04.2009

[3] EUROPEAN COMMISSION: A Roadmap for Moving to a Competitive Low Carbon Economy in 2050, Brussels, 25.5.2011

[4] DIRECTIVE 2010/31/EU OF THE EUROPEAN PARLIAMENT AND OF THE COUNCIL: on the energy performance of buildings, 19.05.2010

[5] Federal Ministry for the Environment, Nature Conservation and Nuclear Safety, Fraunhofer Institute for Systems and Innovation Research ISI: Policy Report, Contribution of Energy Efficiency Measures to Climate Protection within the European Union until 2050, 2012

[6] Statute 7/2006. TMN (V.24): Regarding the Definition of Building Energy Characteristics, 2006 (in Hungarian: Az épületek energetikai jellemzőinek a meghatározásáról)

[7] Thomas L. Saaty: Decision Making with the Analytic Hierarchy Process, Int. J. Services Sciences, Vol. 1, No. 1, pp. 83-98, 2008

[8] Christina J. Hopfe, Godfried L. M. Augenbroe, Jan L. M. Hensen: MultiCriteria Decision Making under Uncertainty in Building Performance Assessment, Building and Environment, Vol. 69, pp. 81-90, 2013

[9] https://www.openstudio.net/, download time: 20.05.2014

[10] http://apps1.eere.energy.gov/buildings/energyplus/, download time: 20.05.2014

[11] Johnny K.W. Wong, Heng Li: Application of the Analytic Hierarchy Process (AHP) in Multi-Criteria Analysis of the Selection of Intelligent Building Systems, Building and Environment, Vol. 43, pp. 108-125, 2008

[12] Alessio Ishizaka, Nam Hoang Nguyen: Calibrated Fuzzy AHP for Current Bank Account Selection, Expert Systems with Applications, Vol. 40, pp. 3775-3783, 2013

[13] Guozhong Zheng, Youyin Jing, Hongxia Huang, Guohua Shi, Xutao Zhang: Developing a Fuzzy Analytic Hierarchical Process Model for Building Energy Conservation Assessment, Renewable Energy, Vol. 35, pp. 78-87, 2010 
[14] G. Kanagaraj, Ashwin Mahalingam: Designing Energy Efficient Commercial Buildings - A Systems Framework, Energy and Buildings, Vol. 43, pp. 2329-2343, 2011

[15] R. Ramanathan: A Note on the Use of the Analytic Hierarchy Process for Environmental Impact Assessment, Journal of Environmental Management, Vol. 63, pp. 27-35, 2001

[16] Yang Yu-lan, Tai Hui-xin, Shi Tao: Weighting Indicators of Building Energy Efficiency Assessment Taking Account of Experts' Priority, J. Cent. South Univ., Vol. 19, pp. 803-808, 2012

[17] Yu-Ting Lai, Wei-Chih Wang, Han-Hsiang Wang: AHP- and Simulationbased Budget Determination Procedure for Public Building Construction Projects, Automation in Construction, Vol. 17, pp. 623-632, 2008

[18] Pablo Aragonés-Beltrán, Fidel Chaparro-González, Juan-Pascual PastorFerrando, Andrea Pla-Rubio: An AHP (Analytic Hierarchy Process)/ANP (Analytic Network Process)-based Multi-Criteria Decision Approach for the Selection of Solar-Thermal Power Plant Investment Projects, Energy, Vol. 66, pp. 222-238, 2014

[19] R. Judkoff, D. Wortman, B. O’Doherty, and J. Burch: A Methodology for Validating Building Energy Analysis Simulations, National Renewable Energy Laboratory, Technical Report NREL/TP-550-42059, 2008

[20] Christina Diakaki, Evangelos Grigoroudis, Dionyssia Kolokotsa: Performance Study of a Multi-Objective Mathematical Programming Modelling Approach for Energy Decision-Making in Buildings, Energy, Vol. 59, pp. 534-542, 2013

[21] Mehmet Kabaka, Erkan Köseb, O־guzhan Kırılmaza, Serhat Burmao־gluca: A Fuzzy Multi-Criteria Decision Making Approach to Assess Building Energy Performance, Energy and Buildings, Vol. 72, pp. 382-389, 2014

[22] Building Information Centre Ltd.: Construction Cost Estimation Guide, 2011, (in Hungarian: Építésügyi Tájékoztatási Központ Kft.: Építőipari költségbecslési segédlet, 2011) 